\title{
Saber pensar
}

\section{Saber pensar desdobra duplo horizonte combinado: de um lado, exige habilidade metodológica; de outro, habilidade política.}

\author{
Pedro Demo*
}

* Professor Titular do Departamento de Sociologia da Universidade de Brasília. E-mail: pedrodemo@uol.com.br.

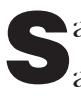
aber pensar é a teoria mais prática que existe, ou a prática mais teórica que existe. Já não cabe separar pensar de intervir, ainda que as duas atividades tenham sua tessitura própria. Pensar é atividade tipicamente mental e intervir é atividade eminentemente prática, mas ambas se entrelaçam e fazem um todo só ${ }^{12}$. Há outra face interessante do saber pensar que é a possível confluência entre epistemologia e política social. Do ponto de vista epistemológico, saber pensar supõe traquejo metódico para lidar de maneira adequada com o conhecimento e seu processo de construção, desconstrução e reconstrução, enquanto, do ponto de vista da política social, saber pensar é pilastra crucial da cidadania ativa, para saber melhor intervir. Dito de outro modo, saber pensar é o emblema da cidadania inteligente. Relembrando Paulo Freire, saber "ler" a realidade, para a desconstruir criticamente e para nela intervir alternativamente. Com isto dizemos também que saber pensar não se restringe ao lado técnico, metódico (métodos e técnicas de pesquisa, por exemplo), mas abarca a politicidade do conhecimento $^{11}$. Se definirmos politicidade como habilidade humana de fazer, em parte, seu destino (deixando a condição de objeto, para assumir a de sujeito participativo e criativo), saber pensar é ferramenta das mais decisivas. Está na base da autonomia possível ${ }^{16}$. Não somos seres completamente autônomos, porque dependemos sempre dos outros (os outros também nos constituem), não sendo viável historicamente autonomia absoluta (destruiria, ademais, a autonomia dos outros). Mas podemos alargar enormemente, indefinidamente, a autonomia, se soubermos pensar, conhecer, aprender ${ }^{6}$. Faz parte do saber pensar não só conquistar espaço próprio, mas saber conviver com o espaço dos outros.

\section{SABER PENSAR E COMPLEXIDADE}

Nosso cérebro é máquina complexa, não linear, de estilo autopoiético ${ }^{26}$, que funciona do ponto de vista do observador, interpretativamente, não passivamente como se fosse máquina de fotografia ou copiador xérox. Nada que está fora entra diretamente na mente, porque é mediado pelos sentidos e pelo cérebro, que constroem, desconstroem e reconstroem a imagem interpretativa, de dentro para fora. Mesmo que quiséssemos copiar, somos incapazes a rigor, porque não reproduzimos, mas reconstruímos a cópia. Entretanto, é sempre possível reduzir o aluno a objeto de cópia, quando o condenamos a ouvir, tomar nota e fazer prova, tudo de maneira reprodutiva. Na prática, porém, assim como nenhum povo copia a cultura dos outros, mas "acultura" a cultura dos outros, somos seres hermenêuticos no sentido de que não nos bastamos com a estrutura sintática recorrente, mas nos embrenhamos sempre na semântica dos significados inevitavelmente subjetivos ${ }^{15}$. O computador, por ser linear, não consegue fazer isso (ainda) ${ }^{13}$ e por isso apenas copia, processa, armazena informação, sendo nisto, porém, de utilidade fantástica. Procede por algoritmo (seqüências lógicas recorrentes), não por desconstrução e reconstrução autopoiética.

O nível da sintaxe é o da gramática - de toda dinâmica complexa pode-se fazer uma gramática, como ocorre com qualquer língua. Tem uma estrutura recorrente, apesar de parecer, para quem não a fala, algo particularmente caótico. O nível da semântica é o da subjetividade irrepetível que, escorando-se nos padrões da gramática, com ela brinca, atribuindo sentidos variados conforme a ocasião, entonação, relação, espaço e tempo. Pode tomar o silêncio ou a ausência como informação e presença, apreender lógica na falta de lógica e vice-versa, vislumbrar em indícios mínimos pista decisiva, criar novidades e refazer tudo sempre. Esta complexidade do saber pensar, que não 
se encerra no manejo lógico, pode ser observada na redefinição de inteligência, como propõe, por exemplo, Hofstadter ${ }^{23}$ (2001), ao discutir diferenças cruciais entre a inteligência humana e a assim dita "artificial":

\footnotetext{
"Ninguém sabe por onde passa a linha divisória entre o comportamento não inteligente e o comportamento inteligente; na verdade, admitir a existência de uma linha divisória nítida é provavelmente uma tolice. Mas, certamente, são capacidades essenciais para a inteligência: responder a situações de maneira muito flexível; tirar vantagens de circunstâncias fortuitas; dar sentido a mensagens ambíguas ou contraditórias; reconhecer a importância relativa de elementos de uma situação; encontrar similaridades entre situações, apesar das diferenças que possam separá-las; encontrar diferenças entre situações, apesar das que possam uni-las; sintetizar novos conceitos, tomando conceitos anteriores e reordená-los de maneiras novas; formular idéias que constituem novidades. Aqui nos encontramos diante de um aparente paradoxo. Por sua própria natureza, os computadores são as criaturas mais inflexíveis, incapazes de desejar e obedientes às regras. Por mais rápidos que possam ser, são também, ao mesmo tempo, a síntese da inconsciência"23.
}

Estamos aqui bem longe do tradicional QI (quociente de inteligência), tendencialmente restrito ao manejo lógico-matemático e ao domínio de conteúdos repetitivos. Não se descarta o manejo lógico-matemático, porque é habilidade importante da mente, mas inteligência não pode ser vista apenas como traquejo linear, por mais que possa ser "virtuoso" (por exemplo, um violinista virtuoso: enquanto apenas reproduzir a peça permanece medíocre, sem falar que a figura mais fundamental é o compositor que criou a peça). Na definição de Hofstadter, nota-se claramente a tessitura complexa não linear da inteligência humana, tipicamente interpretativa, criativa, questionadora, potencialmente disruptiva. Não se satisfaz em apenas afirmar, confirmar, verificar, mas lança-se a desbravar horizontes pela via do questionamento sistemático. Ser inteligente não é apenas surpreender o traçado lógico do cenário, suas linhas recorrentes, mas descobrir o que nele se esconde, o que está submerso, o que poderia significar, que tipo de mensagem propõe, como ocorre com o fotógrafo inteligente. Não se contenta em "retratar", mas busca impor a toda foto um fundo interpretativo surpreendente. Podemos entender mensagens confusas, bem como confundir mensagens, porque na comunicação humana, nada possui contornos estritamente lógicos e definidos, as expectativas são também conflitantes em quem comunica e em quem recebe a comunicação, já que o ambiente humano é sempre naturalmente estratégico, polarizado. Quando nos comunicamos também influenciamos e muitas vezes predomina a influência sobre a comunicação, à revelia do entendimento de Habermas $^{21}$ (1989), que nega o caráter estratégico da ação comunicativa ${ }^{32}$. Sobretudo os sociólogos não conseguem aceitar que a ação comunicativa possa darse neste limbo angélico, porque a politicidade invade todas as entranhas ${ }^{2,3,27,33}$. Quando pessoas inteligentes se comunicam, também se confrontam e estabelecem entre elas relações de enorme complexidade não linear.

\section{SABER PENSAR E PADRONIZAÇÃo MENTAL}

Como toda dinâmica complexa possui traços lineares (códigos), a mente também utiliza, para apreender a realidade, estratégias lineares. É o que ocorre em particular no conhecimento dito científico, mormente em sua versão modernista ${ }^{7}$, devotada a descobrir leis na realidade e embalada pela expectativa de, um dia, poder reduzir tudo o que existe a alguma fórmula matemática absolutamente simples ("everything theory") ${ }^{1,19}$. Imaginava-se que a realidade seria complexa na aparência, na superfície. Pela via da análise (decomposição da realidade em partes cada vez menores) seria viável chegar ao fundo da realidade e lá embaixo encontraríamos estrutura simples, lógico-experimental, matemática. O padrão predominaria sobre a dinâmica. Toda teoria científica tende a acreditar nisso, porque reduz o complexo a estruturas mais simples, à medida que traça regularidades, que não só seriam mais facilmente manejáveis pelo método científico (positivista, neste caso) ${ }^{20}$, como principalmente seriam a essência do fenômeno (coincidência entre epistemologia e ontologia $)^{10}$. Esta expectativa desmoronou com o advento de posições não só críticas, mas principalmente autocríticas do conhecimento científico no assim chamado "pós-modernismo" 29,31 , capazes de perceber seus limites perante a realidade indevassável pela via das padronizações recorrentes. Tais padronizações metódicas não captam a dinâmica, mas apenas a regularidade da dinâmica.

Mesmo assim, este procedimento obteve resultados e glórias incontáveis e decisivas, como se observa no rol das tecnologias inventadas através dos tempos, em especial nas tecnologias bélicas conhecidas e informáticas atuais. A mente possui este lado também. 
Perante o desconhecido, tende a proceder em três lances mais ou menos típicos: primeiro, procura no desconhecido o que haveria de conhecido, familiar; segundo, procura o que se repete; terceiro, se nada disso funciona, impõe uma ordem mental e damos a isto o nome de teoria. Nesta trajetória, entretanto, aparece o reverso da medalha intrinsecamente, à medida que o esforço por padronizar é reconstrutivo da realidade, não reprodutivo. Não temos na mente a realidade como tal, mas imagem reconstruída dela, de dentro para fora, autopoiética. Trai o lado interventor deste procedimento, porque tentamos prender a dinâmica em estruturas que condizem muito mais com a expectativa do método, do que com a dinâmica não-linear. Para entender o não-linear recorremos ao truque sempre em parte bisonho de o linearizar. Na teoria está um esforço de estruturação metódica da realidade, não a realidade como tal, que sempre acaba nos escapando. Não adianta procurar um fundo do que não tem fundo.

Temos, assim, que reconhecer a face padronizadora da mente e seus êxitos monumentais, por mais que hoje isto não nos satisfaça. Pesquisar não é reproduzir a realidade, mas construir interpretações inteligentes. Por não refletirem estas diretamente a realidade, pois são interpretações subjetivas, ainda que metodicamente reguladas, as explicações são apenas aproximações possíveis e sempre frágeis, cuja finalidade não é encerrar, mas animar a discussão infinda. Observando nossas tecnologias mais sofisticadas, apesar de serem artefatos lineares, revelam criatividade considerável, porque no fundo do conhecimento não emergem apenas procedimentos lógicos recorrentes, mas a rebeldia contestatória. Inventamos tecnologias porque o que estava dado não era tudo que desejávamos. A realidade que se nos apresenta não é o limite de atuação, mas o palco infindo de desbravamentos irrequietos. Por trás do que se mede, observa, cerca, há dinâmicas indomáveis inscritas na própria tessitura dialética da natureza. Esta é unidade de contrários, não apenas superfícies lisas e tranqüilas. Por exemplo, entender o que não se diz no que se diz, tomar o silêncio como mensagem, falar muito para não dizer nada implicam o manejo criativo da semântica da linguagem, tipicamente complexa não linear. Mas pode contribuir muito para sua compreensão o esforço de padronização de tais dinâmicas, desde que não se reduza o complexo ao simples, mas tomemos truques simplificadores como portas de entrada para um mundo sem fundo. Assim, perceber num instante, por obra do bom senso, em dado cenário muito complicado qual seria a solução mais adequada, é expressão de criatividade acentuada, mas igualmente da capacidade de padronização. Quem vê tudo, não vê nada. Trata-se de ver, num emaranhado de fatores, aquele ou aqueles que seriam os mais estratégicos e ficar com eles. Há nisto muito de criatividade tipicamente não linear, mas também a argúcia padronizadora que é capaz de perceber linhas na falta de linhas. Ao final, em ambos os casos temos intervenções interpretativas, porque, mesmo padronizando, a mente o faz para interpretar, não para reproduzir.

\section{POLITICIDADE DO SABER PENSAR}

Conhecimento é a habilidade de questionamento. Enquanto não se questiona, não se conhece. Apenas se reproduz. É o que sempre alegou a "teoria críti$\mathrm{ca}^{17}$ - a qualidade da teoria está em sua habilidade crítica, porque, ao tentar compreender a realidade, não a retrata, mas a desconstrói e reconstrói. Conhecimento possui potencialidade disruptiva, no sentido de que seu signo é rebeldia, confronto, contestação. Porque não aceitamos a realidade dada ou não a tomamos como horizonte final, nos pomos a contestar, para interferir, superar. Há 40 mil anos ainda morávamos em cavernas. Hoje moramos em Nova Iorque. Se compararmos uma caverna com Nova Iorque, temos uma idéia do progresso que inventamos, a preço do conhecimento disruptivo, por mais que esta trajetória esconda incontáveis problemas éticos ${ }^{7}$. Conhecimento é dinâmica ambígua: o mesmo conhecimento que esclarece, emancipa, é o mesmo que imbeciliza, convive com censura, coloniza ${ }^{22}$. Esta condição apenas escancara ainda mais a politicidade intrínseca do conhecimento: com ele não só "pensamos", "conhecemos", sobretudo interferimos. Ao contrário do que o positivismo prega, o ambiente político não é espúrio, enfiado artificialmente de fora, mas mora dentro da mente humana, porque não sabemos pensar sem compromisso subjetivo e social, sem falar da localização multicultural. Neste sentido, ideologia não é excrescência, mas contraluz. Método não é apenas procedimento formal, é interferência. Precisamente é procedimento de interferência, cuja vantagem é de ser metódico, sistemático, testável.

Os termos não podem ser embaralhados logicamente. Lógica é procedimento formal, faz parte do mundo da forma. Não prova, por isso, a existência de nada, apenas possível dedução/indução formal. Existência não se reduz à lógica, porque na forma não mora ninguém. Temos forma, mas não somos apenas forma. Existir é modo de ser e de vir a ser ${ }^{9}$ - há nele 
"modo", forma, mas há sobretudo história irreversível. Esta é tipicamente complexa, não linear. Existência implica existências anteriores, por origem histórica e evolucionária, mas a elas não se reduz, nem a elas poderia voltar. Por isso, qualidade formal e política, logicamente horizontes diversos, se entrelaçam no existir. Uma está dentro da outra, sendo uma da ordem dos meios (qualidade formal), e a outra dos fins (qualidade política). Facilmente separamos as coisas - procuramos qualidade política fora, em situações marcadas não tanto pela politicidade, quanto por estereótipos da "política". Na universidade, extensão está separada do currículo, o que insinua que a formação política não seria curricular. Outros vão procurar a formação política do aluno no "centro acadêmico", sem perceber que este lugar é importante, mas nem de longe o mais profundo. O mais profundo está no próprio exercício da qualidade formal. À medida que abandonamos o argumento de autoridade em favor da autoridade do argumento, aprendemos a argumentar, fundamentar, não a impor, aceitamos escutar os outros com atenção e responder civilizadamente com contra-argumentos, partilhamos o saber pensar em nome de consensos frágeis e democráticos, não estamos apenas realizando a qualidade formal, mas intrinsecamente a qualidade política.

Reconhecemos hoje mais facilmente que pesquisa é princípio educativo. Com ela não só exercitamos método, forjamos sobretudo autonomia ${ }^{4}$. O aluno constitui-se sujeito mais visivelmente, à medida que descobre o lado disruptivo do conhecimento, é chamado a tornar-se autor, maneja conhecimento com elegância e habilidade ${ }^{18,28}$. "Educar pela pesquisa" tornou-se, aos poucos, referência fundamental da formação do aluno, porque expressa atividade autopoiética, reconstrutiva e política. Por isso, saber pensar desdobra duplo horizonte combinado: de um lado, exige habilidade metodológica; de outro, habilidade política. Para saber mudar a história nada é mais útil que saber pensar ${ }^{14,25,30}$.

Quando desconstruímos e reconstruímos a realidade e respectivas teorias, não estamos apenas praticando traquejo metodológico, estamos, acima de tudo, interferindo de modo inteligente na realidade, realizando um dos horizontes mais fundamentais da cidadania: saber pensar para saber intervir. Cidadania supõe procedimentos democráticos, em nome do bem comum. Primeiro, não pode ser cidadania que destrói a cidadania dos outros. Postula a convivência possível, dentro de consensos alimentados pela autoridade do argumento ${ }^{5}$. Segundo, exige a comunidade capaz de convencer sem vencer. Trata-se do apreço por esfera pública da discussão aberta, na qual melhor se resolvem os problemas, sem recurso a truculências. Cabe argumentar, não impor. Terceiro, pede consensos relativos (não relativistas), porque somente consensos relativos são discutíveis, tão profundos, quanto frágeis. Entre muitos problemas solúveis através de consensos comuns, há outros insolúveis, tendo em vista que somos problema apenas em parte solúvel. O poder sempre tem a tentação de traçar na sociedade linhas retas, como dizem autores da "lógica difusa" ${ }^{4}$, porque, em vez de consensos democráticos relativos, prefere a força. Quem sabe pensar não usa a força, mas o argumento. Ao mesmo tempo, quem sabe argumentar, promove o contra-argumento. Jamais fecha a discussão, porque o sentido da discussão não é fechar, mas abrir para novas e infindáveis discussões.

Esta é a dinâmica não linear do conhecimento: desconstrói e reconstrói de maneira permanente - o que desconstrói, reconstrói; o que reconstrói, volta a desconstruir. Trata-se de dinâmica irreversível, como são evolução e história. Se a evolução começasse de novo (se é que começou), não teria a menor condição de resultar no mesmo processo atual, bem como se a história começasse de novo, não seria cabível repetir o mesmo trajeto histórico conhecido. Somos todos em certo sentido, iguais. Em outro sentido, diferentes. Esta combinação não linear de igualdade e diferença perfaz nosso modo de ser e de vir a ser. Somos iguais, porque somos diferentes e vice-versa. Quando olho uma foto da infância, reconheço-me como sendo ainda eu, mas em outro momento. Mantemo-nos os mesmos, porque mudamos. Há na natureza um horizonte complexo não linear que se recusa a repetir-se. Reconstrói-se indefinidamente. Ser inteligente não pode, por isso, reduzir-se a truques repetitivos. Sua elegância maior está na habilidade semântica capaz de perceber o erro em toda verdade e a verdade em todo erro.

\section{REFERÊNCIAS BIBLIOGRÁFICAS}

1. Barrow JD. Teorias de tudo - a busca da explicação final. Rio de Janeiro: J. Zahar; 1994.

2. Bourdieu P. A economia das trocas lingüísticas. São Paulo: EDUSP; 1996a.

3. Bourdieu P. Razões práticas - sobre a teoria da ação. Campinas: Papirus; 1996b.

4. Calazans J, organizador. Iniciação científica: construindo o pensamento crítico. São Paulo: Cortez; 1999.

5. Connolly WE. Neuropolitics - thinking, culture, speed (theory out of bounds). Minneapolis: University of Minnesota Press; 
2002.

6. Demo P. Complexidade e aprendizagem - a dinâmica não linear do conhecimento. São Paulo: Atlas; 2002a.

7. Demo P. Conhecimento moderno - sobre ética e intervenção do conhecimento. Petrópolis: Vozes; 1999.

8. Demo P. Educar pela pesquisa. Campinas: Autores Associados; 1996.

9. Demo P. Introdução à Sociologia - complexidade, interdisciplinaridade e desigualdade social. São Paulo: Atlas; 2002b.

10. Demo P. Metodologia do conhecimento científico. São Paulo: Atlas; 2000a.

11. Demo P. Politicidade - razão humana. Campinas: Papirus; 2002.

12. Demo P. Saber pensar. São Paulo: Cortez; 2000.

13. Dreyfus HL. What computers still can't do - a critique of artificial reason. Cambridge: The MIT Press; 1997.

14. Fonseca V. Aprender a aprender - a educabilidade cognitiva. Porto Alegre: Artmed; 1998.

15. Foucault M. A hermenêutica do sujeito. São Paulo: Martins Fontes; 2004

16. Freire $\mathrm{P}$. Pedagogia da autonomia - saberes necessários à prática educativa. Rio de Janeiro: Paz e Terra; 1997.

17. Freitag B. A teoria crítica - ontem e hoje. São Paulo: Brasiliense; 1986.

18. Galiazzi MC. Educar pela pesquisa - ambiente de formação de professores de ciências. Ijuí: Unijuí; 2003.

19. Gribbin J. The search for superstrings, symmetry, and the theory of everything. New York: Little, Brown and Company; 1998.
20. Haack S. Defending science within reason - between scientism and cynicism. New York: Prometheus Books; 2003.

21. Habermas J. Consciência moral e agir comunicativo. Rio de Janeiro: Tempo Brasileiro; 1989.

22. Harding S. Is Science multicultural? Postcolonialisms, feminisms, and epistemologies. Bloomington and Indianapolis: Indiana University Press; 1998.

23. Hofstadter DR. Gödel, Escher, Bach - um entrelaçamento de gênios brilhantes. Brasília: UnB; 2001

24. Kosko B. The fuzzy future - from society and science to heaven in a chip. New York: Harmony Books; 1999.

25. Leão EC. Aprendendo a pensar. Petrópolis: Vozes; 1977.

26. Maturana H. Cognição, ciência e vida cotidiana. Organização de Magro C e Paredes V. Belo Horizonte: Humanitas/UFMG; 2001.

27. Mészáros I. O poder da ideologia. São Paulo: Boitempo; 2004.

28. Moraes R, Lima VMR, organizadores. Pesquisa em sala de aula - tendências para a educação em novos tempos. Porto Alegre: EDIPUCRS; 2002.

29. Morin E. Ciência com consciência. Rio de Janeiro: Bertrand Brasil; 1996.

30. Novak JD, Gowin DB. Aprender a aprender. Porto: Plátano; 1995.

31. Prigogine I. O fim das certezas - tempo, caos e as leis da natureza. São Paulo: UNESP; 1996.

32. Rivera FJU. Agir comunicativo e planejamento social (uma crítica ao enfoque estratégico). Rio de Janeiro: Fiocruz; 1995.

33. Sfez L. Crítica da comunicação. São Paulo: Loyola; 1994.

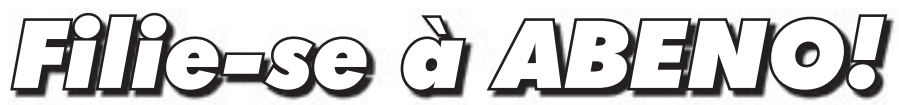

Você poderá receber a Revista ou acessá-la "on-line" para conhecer os artigos mais importantes da área de ensino odontológico.

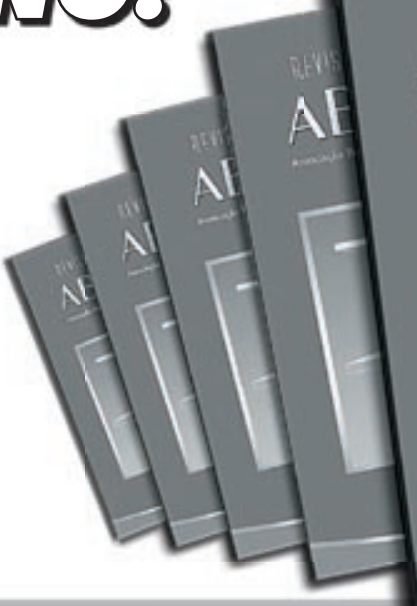
ABENO

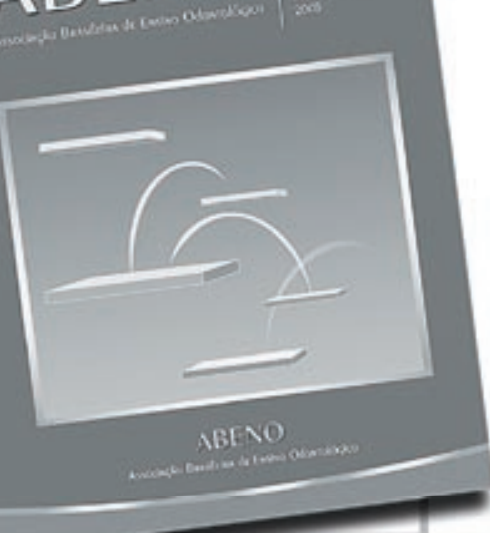

